\title{
Immediate and Long Term Evolution of Valve Replacement in Children Less than 12 Years Old
}

\author{
Fernando Antibas Atik, Altamiro Ribeiro Dias, Pablo M. A. Pomerantzeff, Miguel Barbero-Marcial, \\ Noedir Antonio Groppo Stolf, Adib Domingos Jatene
}

São Paulo, SP - Brazil

\begin{abstract}
Objective - The aim of this work was the follow-up and evaluation of valve replacement in children under 12 years of age.

Methods - Forty-four children less than 12 years old were underwent valve replacement at INCOR-HCFMUSP between January 1986 and December 1992. Forty (91\%) were rheumatic, 39 (88.7\%) were in functional classes II or IV, 19 (43.2\%) were operated upon on an emergency basis, and $6(13.6 \%)$ had atrial fibrillation. Biological prostheses $(B P)$ were employed in 26 patients $(59.1 \%)$, and mechanical prostheses (MP) in 18 (40.9\%). Mitral valves were replaced in $30(68.7 \%)$, aortic valves in 8 (18.2\%), a tricuspid valve in 1 (2.3\%), and double (aortic and mitral) valves in 5 (11.4) of the patients.
\end{abstract}

Results - Hospital mortality was of $4.5 \%$ (2 cases). The mean follow-up period was 5.8 years. Re-operations occurred in $63.3 \%$ of the patients with BP and in $12.5 \%$ of those with $M P(p=0.002)$. Infectious endocarditis was present in $26.3 \%$ of the $B P$, but in none of the cases of MP $(p=0.049)$. Thrombosis occurred in $2(12.5 \%)$ and hemorrhage in one (6.5\%) of the patients with a MP. Delayed mortality occurred in $5(11.9 \%)$ of the patients over a mean period of 2.6 years; four had had BP and one had a MP (NS). Actuarial survival and re-operation-free curves after 10 years were respectively, $82.5 \pm 7.7$ (SD)\% and $20.6 \pm 15.9 \%$.

Conclusion - Patients with MP required fewer reoperation, had less infectious endocarditis and lower late mortality rates compared with patients with bioprostheses. The former, therefore, appear to be the best valve replacement for pediatric patients.

Key words: cardiac valve replacement, rheumatic fever, children

Instituto do Coração do Hospital das Clínicas - FMUSP.

Mailing address: Fernando Antibas Atik - Av. Chibarás, 626/101 - 04076-003 São Paulo, SP - Brazil.

Received on 2/25/99

Accepted on 8/11/99
The high prevalence of rheumatic fever in infants and adolescents draws attention to the peculiarities of the disease, which frequently causes serious valves dysfunction often in association with conditions of rheumatic activity of the cardiac muscle. Due to their important hemodynamic repercussions, such conditions may at times require urgent surgical intervention ${ }^{1}$.

Conservative surgical procedures, a primary approach to these cases, are often not possible due to pathological alterations present in cardiac valves. On the other hand, valve replacement in infants and adolescents has its own set of difficulties, in particular, which prostheses types and size to use.

The aim of this work is to present the immediate and long-term experience of our valve replacement service with children under 12 years of age, with the aim of identifying the ideal prosthesis for use at this age group.

\section{Methods}

Forty-four patients under 12 years of age who underwent to valve replacement at the Heart Institute, Hospital of Clinics, University of São Paulo Medical School between January 1986 and December 1992, were retrospectively analyzed.

Twenty-three (52.3\%) were males between 2 and 12 years of age (average age 10 years). Their valve diseases were of rheumatic in origin in $40(91 \%)$, degenerative in 2 $(4.5 \%)$ and congenital in $2(4.5 \%)$ of the cases. Twenty (45.5\%) of the patients were in preoperative NYHA functional class IV, $19(43.2 \%)$ were in functional class III and 5 $(11.3 \%)$ were in functional class II of the NYHA scale. Nineteen $(43.2 \%)$ had emergency operations, $6(13.6 \%)$ had chronic atrial fibrillation and 13 (29.5\%) showed laboratory and scintigraphic evidence of rheumatic activity.

Valve replacements were performed in the mitral position in 30 patients $(68.2 \%)$, in the aortic position in $8(18.2 \%)$ and in the tricuspid position in one (2.3\%). Five (11.3\%) patients were underwent double mitral and aortic valve replacement. 
Twelve patients had previously undergone mitral valve replacement, performed twice in two of them, of which one had a tricuspid, the other mitral +aortic prostheses. Previous mitral prostheses had been biological in nine and of dura mater in one patient; patients twice-operated upon had mechanical prostheses implanted only in the second operation. Both the patient with the tricuspid exchange and the one who had a double exchange received biological prosthesis. The average timeinterval following the firstintervention was 4.3 yearsfor the mitral, 9 years for the tricuspid and 2 years for the double prostheses.

Three patients had undergone previous conservative procedures on the mitral valve whose average durability had been 3.3 years.

Regarding the type of prostheses used in the 44 operations reported in this study, 26 (59.1\%) of the patients received biological (Biocor, INCOR, Labcor) and $18 \mathrm{me}-$ chanical (St. Jude, Carbomedics, Omnicarbon, Sorin) prostheses. In the mitral position, biological (18) predominated over mechanical (12) prostheses. Five biological versus three mechanical prostheses were utilized in the aortic position, one mechanical prostheses were used in the tricuspid position and of the 5 patients who underwent to the double exchange, three had biological prostheses.

Associated procedures consisted of tricuspid valve repair surgery in 11 patients, mitral valve repair surgery in 4 , myocardial biopsies in two, and left atrial thrombectomy in one case. Enlargement of the aortic ring with bovine pericardium was required for size 21 prostheses implants in two patients and of size 19 in another.

Sizes of prostheses implanted in the various cardiac valves are shown in table I.

Extracorporeal circulation at $25-28^{\circ} \mathrm{C}$ hypothermia was used in all patients operated upon: myocardial protection was afforded by cold crystalloid solution or blood. Average perfusion time was 102.3 minutes and anoxia 70.5 minutes.

Native cardiac valve defects were as follows: retractions in 14 cases, ring dilatation in 9 , chord rupture in 8 , calcification in 5 , prolapse in 5 , vegetation in 5 , fibrosis in 4 , thickening in 4 and chord lengthening in 2 . Regarding macroscopic characteristics on previously implanted prostheses, calcification was observed in 12 , ring dilatation in 5 , thickening in 2 , rupture in 2 , stenosis in 3 , retraction in 1 and perivalve escape in one.

Thirty-five (83.3\%) of the subjects were followed as out-patients for periods varying between 1 month and 11 years ( 5.82 years average). Long term follow-up for more than 5 years was possible for $23(54.8 \%)$ patients.

Patients who received mechanical prostheses were kept on the anticoagulant sodium warfarin, INR levels were maintained between 2 and 2.5 .

\begin{tabular}{|lccccccccc|}
\hline \multicolumn{1}{|c|}{ Table I - Survey of the size of prostheses implanted in the different } \\
cardiac valves
\end{tabular}

Valve replacement in childrem less than 12 years old

To compare immediate and long-term effects of biological and mechanical prostheses statistically, Fisher's exact test and the chi-square test were employed. Values of $\mathrm{P}<0.05$ were considered statistically significant. Estimates of survival and no-re-operation probabilities were performed using the Kaplan-Meier; the descriptive probability level was determined using the log-rank test.

\section{Results}

Postoperative periods were characterized by the low cardiac output in 11 patients, cardiac arrhythmia in 5, bronchopneumonia in 5 , bleeding in 4 , pericarditis in 4 , acute renal failure in 3 , septicemia in 1 and an ischemic stroke in one.

Two (4.5\%) of the patients died during the immediate postoperative period: both had been submitted to emergency mitral valve replacement with mechanical prostheses. Death was due to cardiogenic shock in both patients who preoperatively, had evidence of active rheumatic illness, acute pulmonary edema and clinical signs of undernutrition. One of the patients had already been operated on and shown development of coagulopathy upon termination of extracorporeal circulation. Table II presents the survey of hospital deaths, according to the type of prostheses used. Due to the small number of patients, no statistically significant differences were observed.

During the patients' follow-up periods, the most pronounced complications were due to calcification of the biological prostheses in $14(73.7 \%)$ patients, three of whom showed no significant valve dysfunction. The presence of prosthetic infectious endocarditis occurred in $5(14.3 \%)$ patients, all involving biological prostheses, a statistically significant finding (table III). Complications of the mechanical prostheses were caused by faulty anticoagulation control, two patients having thrombosis (see re-

\begin{tabular}{|c|c|c|c|}
\hline \multicolumn{4}{|c|}{$\begin{array}{c}\text { Table II - Differences between biological and mechanical } \\
\text { prostheses in regards to hospital mortality }\end{array}$} \\
\hline & Biological & Mechanical & Total \\
\hline Patients & 26 & 18 & 44 \\
\hline \multicolumn{4}{|l|}{ Preoperative FC } \\
\hline II & 4 & 1 & 5 \\
\hline III & 12 & 7 & 19 \\
\hline IV & 10 & 10 & 20 \\
\hline In-hospital mortality & 0 & 2 & $2(4,5 \%)$ \\
\hline
\end{tabular}

\begin{tabular}{|c|c|c|c|}
\hline \multicolumn{4}{|c|}{$\begin{array}{l}\text { Table III - Differences between biological and mechanical } \\
\text { prostheses regarding long term morbidity and mortality }\end{array}$} \\
\hline & Biological & Mechanical & $P$ \\
\hline Patients & 19 & 16 & - \\
\hline Re-operation & $12(63,2 \%)$ & $2(12,5 \%)$ & 0,002 \\
\hline Infectious endocarditis & $5(26,3 \%)$ & 0 & 0,049 \\
\hline Long-term mortality & $4(21,1 \%)$ & $1(6,3 \%)$ & $0,342 *$ \\
\hline
\end{tabular}


operations) and one with excessive menstrual bleeding leading to hypovolemic shock.

Fourteen patients $(40 \%)$ were re-operated upon, three $(8.6 \%)$ of these were re-operated upon twice. The average time interval between the two operations was 4.5 years, and between the second and the third 1.5 years. Biological prostheses were present in $12(63.2 \%)$ patients, two in the aortic position. Mechanical prostheses were present in $2(12.5 \%)$ of the patients, both in the mitral position. A statistically significant difference between the type of prostheses and the possibility of re-operation is shown in table III.

The reasons for re-operation in cases of biological prostheses were calcification and stenosis in $8(66.7 \%)$ of the patients, calcification and rupture in $2(16.7 \%)$, infectious endocarditis in one $(8.3 \%)$ and faulty closure of the posterior tricuspid due to a manufacturer's defect in another. Due to thrombosis, mechanical prostheses required replacement in both cases.

The size of the prostheses was not the reason for re-operation of any of the patients, even though 4 of the 14 re-operated patients had received prostheses of a greater diameter.

Operation-free curves (fig.1) demonstrated that the estimated probabilities of maintenance of the original prostheses after 2,5 and 10 years were respectively, $93.7 \%$, $64.2 \%$ and $20.6 \%$. When these results were evaluated in accordance with the type of prostheses used (fig.2), mechanical prostheses proved to be superior to biological ones $(\mathrm{P}=0.022)$.

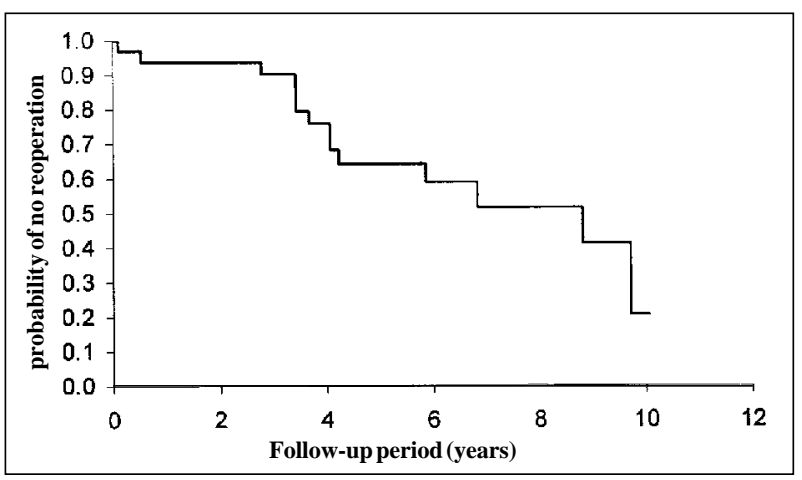

Fig. 1 - Estimate of probability of no reoperation (Kaplan-Meier method) - total sample.

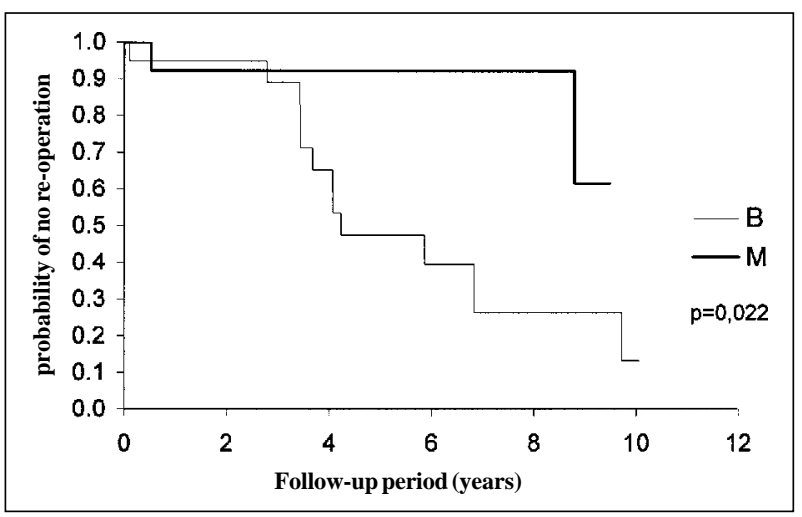

Fig. 2 - Estimate of probability of no re-operation (Kaplan-Meier method) - sample stratified according to type of prosthesis.
Five $(11.9 \%)$ of the patients died during long-term follow-up, which was an average period of 2.6 years. Four of these had received biological prostheses. One of them died suddenly due to cardiac arrhythmia; at necropsy neither the cause of death nor prosthesis's abnormalities were revealed. Three patients experienced dysfunctions secondary to early calcification and were re-operated upon. One died due to an aortic iatrogenic lesion during median sternotomy. The other two patients developed infectious endocarditis at the site of the prosthesis.

One patient had a mechanical prosthesis at the mitral position and developed thrombosis at this site due to a cerebral vascular accident. He underwent thrombi removal followed by a renewed change of the mitral valve with a biological prosthesis, because of infections endocarditis of this prosthesis accompanied by septicemia and cardiogenic shock.

No statistically significant difference between the type of prosthesis used and delayed mortality occurred (table III).

Actuarial survival curves (fig.3), demonstrated that after 2, 5 and 10 years, estimated probabilities were respectively, $93.3 \%, 82.5 \%$ and $82.5 \%$ (fig. 4 ). The group comprising recipients of mechanical prostheses had better survival curves, although in a statistically non-significant manner, than those with biological prostheses.

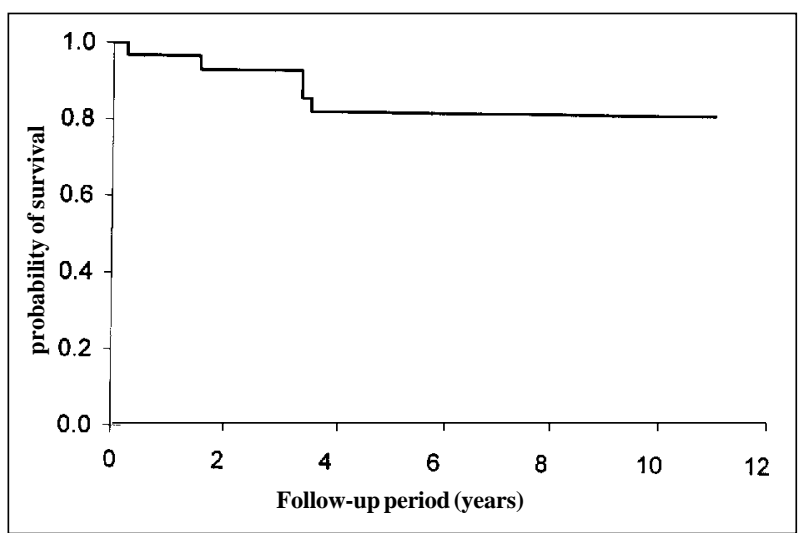

Fig. 3 - Estimate of probability of survival (Kaplan-Meier method) - total sample.

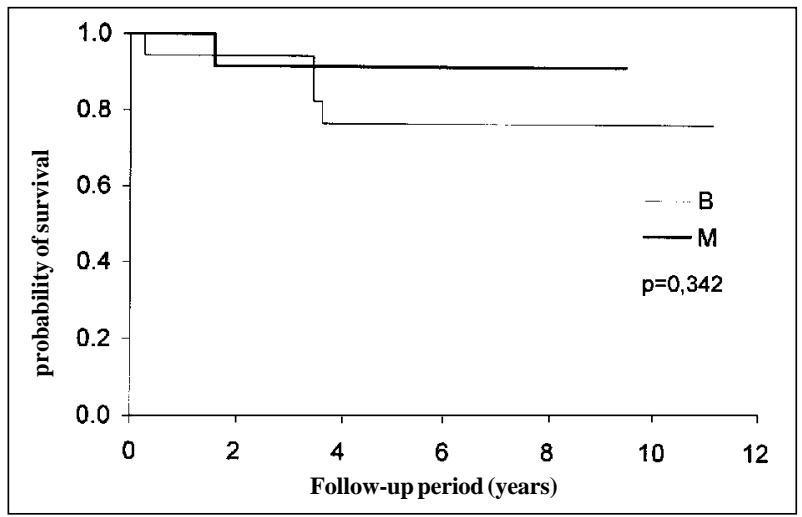

Fig. 4 -Estimate of probability of survival (Kaplan-Meier method)- sample stratified according to type of prosthesis. 
Of the 25 patients being followed up to the present time, the majority ( 22 cases) are in functional class I; three of them show signs on echocardiography of calcification without valve dysfunction. The three remaining patients have biological mitral prosthesis and clinically, belong to functional classes II ( 2 cases) and III (one case). They show significant prosthesis degradation due to calcification accompanied by marked stenosis and insufficiency and await re-operation.

\section{Discussion}

Surgical treatment of valve disease in children and adolescents constitutes a challenge for the surgeon. It acquires aggravating characteristics due to the current high prevalence of rheumatic disease in our midst. Many affected children have advanced degrees of cardiac failure (functional classes II or IV), of rheumatic myocardial activity, requiring at times, emergency operations to correct serious hemodynamic disturbances ${ }^{2}$.

The existence of previous operations whether conservative or not and of varying degrees of malnutrition, are other factors causing this group of patients to exhibit high immediate and delayed rates of mortality, as demonstrated in this study in which $88.7 \%$ of the patients were in functional class II/IV, $43.2 \%$ had emergency operations, $34.1 \%$ had had previous cardiac operations, resulting in a hospital mortality rate of $4.5 \%$. Immediate mortality indexes in the literature vary from zero to $13 \%$. Robbins et $\mathrm{al}^{3}$ defined less than 2 years of age, presence of previous operations and double valve replacement as hospital mortality risk factors. According to Vosa et $\mathrm{al}^{4}$, mortality is believed to be related to the correction of complex congenital anomalies or to the level of myocardial involvement in cases of rheumatic and degenerative valve pathologies.

In the majority of the cases, serious pathological cardiac valve alterations prevent the use of repair interventions, rendering prosthetic valve replacement obligatory. The use of this procedure becomes controversial when performed on children as opposed to adults ${ }^{5}$.

Due to the reduced size of the valve ring, specially in small children, it is of fundamental importance to implant prostheses large enough to allow for somatic growth and no need for re-operation due to functional stenosis ${ }^{1}$. Ibrahim et al ${ }^{6}$ advocate that the smallest initial size should be $25 \mathrm{~mm}$ for the mitral and $21 \mathrm{~mm}$ for the aortic position, respectively. At times, enlargement of the aortic ring, becomes necessary; in this study it was performed in three patients who had good early and late evolution and no requirement for re-operation. None of the patients in the present study required re-operation directly because of the small size of the prostheses, a result the same as that previously explained ${ }^{1}$, by the presence of patients with rheumatic fever, a condition frequently leading to valve regurgitation associated with ring dilatation.

The type of prostheses to be implanted has given rise to discussion for decades. However, the majority of authors argue in favor of the use of mechanical prostheses only in patients of this age 7 . This tendency is explained by the fact that long-term follow-up of the evolution of bioprostheses has demonstrated a high incidence of complications connected to degradation with precocious calcification, requiring re-operation ${ }^{8-10}$. Antunes et al ${ }^{11}$ found only $19 \%$ of the living patients in their case files to have kept retained their original prostheses after seven years. The rate of degeneration was $22.4 \%$ in patients per year in comparison with structural faults in $4 \%$ of adult patients per year. In our experience, the probability of patients maintaining their original prostheses was $47.5 \%$ and $13.2 \%$ after follow-up periods of 5 and 10 years, respectively.

This biodegradation process is not innocuous; it leads to the death of many patients during the long period of waiting for a new operation, a problem not unusual in our service. In addition, morbidity and mortality at re-operation are high, as attested by our experience that shows $25 \%$ mortality, not to mention the high cost of hospitalization.

The causes of bioprostheses calcification have been attributed to repeated rheumatic bursts, leading to increased alkaline phosphatase activity with increased calcium turnover ${ }^{12}$, the process of porcine prostheses preservation with glutaraldehyde, further promoting calcium deposition. The pathological mechanism is the calcification and fibrosis of the cusps, leading to deformity and rigidity and valve stenosis.

Due to this, casuistic studies have reflected the actual tendency to use exclusively mechanical prostheses. Longterm follow-up has shown smaller mortality indexes, with acceptable levels of morbidity, related mainly to alterations in coagulation. Anticoagulation methods are a major subject of discussion.

The type of mechanical prostheses has not influenced these favorable results, even though groups investigated have mainly been composed of patients with congenital anomalies ${ }^{5,6,13,14}$. Harada et al $^{5}$, using St. Judes heart valve, found no early mortality rates, estimated survival times after 10 years being $90.8 \%$, and free of complications of $84.7 \%$ over the same time period. Employing the same prosthesis, Ibrahim et al ${ }^{6}$ obtained even better results with no need for re-operation and/or occurrence of delayed deaths, or either of these. Using different types of mechanical prosthesis in various valve positions, we documented a re-operation-free curve at 5 and 9 years was of $92.3 \%$ and 61.55 , respectively; the survival curve over the same periods was of $91.6 \%$.

Studies of patients with rheumatic fever ${ }^{1,2,12}$, who are considered by many authors to be more serious patients than those with congenital anomalies, show results similar to the former. Antunes et al ${ }^{1}$ in the casuistic study of 352 patients under 20 years of age who underwent valve replacement with mechanical prosthesis obtained an early mortality rate of $6.3 \%$ and a delayed rate of $5.3 \%$ patients per year; this figure is significantly higher in a subgroup that underwent double valve replacement. The actuarial survival curve at seven years was $76 \%$ and the reoperation-free curve $88 \%$; interestingly, these results are 
statistically similar to those obtained with a group of operated adults over the same period.

According to our patient files, the estimated survival and re-operation-free probabilities at 5 years were $91.6 \%$ and $92.3 \%$, respectively.

Which anticoagulation method to use is a controversial issue to be decided. The tendency towards trauma, the desire to achieve pregnancy, the presence of atrial fibrillation and difficulties in maintaining an adequate therapeutic level due to psychological or socio-economic problems of adherence to treatment are the responsible factors. This question is of special importance to us because often no adequate clinical and laboratory evaluation of coagulation levels exists, leading to the occurrence of thromboembolism on the one hand and of hemorrhagic phenomena on the other.

Due to such dangerous irregularities in anticoagulant treatment, Abid et al ${ }^{12}$ contraindicate this therapy in a special group of patients having sinus rhythm and hemodynamic stability and have not observed an increased incidence of complications. Verrier et al ${ }^{15}$ suggest that children in sinus rhythm, recipients of aortic prostheses, can be safely treated with aspirin, dipyridamole, or both; results are however controversial among different authors.

Cabalka et al ${ }^{13}$, reported relatively high incidence of early thrombosis (between 3 and 6 months) that occurred only in patients without medication. Therefore, by indicate anticoagulation from 6 to 9 months for recipients of mitral prostheses, preferring to reduce therapeutic levels, since after this time, the tendency toward bleeding supplants the risk of thromboembolism.

Robbins et $\mathrm{al}^{3}$, however, use oral anticoagulants in all patients, independently of the valve position. By adopting the same approach, we obtained prosthetic thrombosis in $12.5 \%$ and hemorrhage in $6.25 \%$ of the patients, all of whom used the medication irregularly.
Dental problems, upper airway infections and trauma in children have influenced us to adopt vigorous prophylaxis for infectious endocarditis in valve prostheses. In this study, five (14.3\%) patients acquired endocarditis, which led to the death of three of them. This serious complication has been reported by others, with slightly lesser frequency, but with a similar course of evolution. Although the incidence is similar regarding the type of prostheses ${ }^{16}$, Robbins et al ${ }^{3}$ reported a greater incidence with mechanical ones, in contrast to our results. However, samples are too small to allow for final conclusions.

Recent studies ${ }^{17,18}$ have reported experiments with homografts and Ross precedure in aortic valve disease. Results in a selected number of patients are encouraging, showing good early evolution. However, this technique is little known among surgeons, painstaking , and of doubtful results in inexperienced centers.

In conclusion, valve replacement in children is a highrisk procedure, showing considerable rates of immediate and long-term mortality in seriously ill patients. Early calcification, leading to a high rate of re-operations over a short time, renders the use of bioprotheses impraticable for this age group. Mechanical prostheses show a lower rate of re-operation, infectious endocarditis and long-term mortality. Rigorous anticoagulation control and prevention of infectious endocarditis are the only means of reducing longterm complications. These prostheses seem, therefore, to be the best valve replacement in this age group, even in populations with hazardous anticoagulation control, where alternative methods could be used.

\section{Acknowledgments}

To Rita Helena Antonelli Cardoso and Carine Sovalli for the statistical analyses performed.

\section{References}

1. Antunes MJ, Vanderdonck KM, Sussman MJ. Mechanical valve replacement in children and teenagers. Eur J Cardiothorac Surg 1989; 3: 222-8.

2. John S, Ravikumar E, Jairaj PS, Chowdhury U, Krishnaswami S. Valve replacement in the young patient with rheumatic heart disease. J Thorac Cardiovasc Surg 1990; 99: 631-8.

3. Robbins RC, Bowman FO, Malm JR. Cardiac valve replacement in children: a twenty year series. Ann Thorac Surg 1988; 45: 56-61.

4. Vosa C, Renzulli A, Lombardi PF, Damiani G. Mechanical valve replacement under 12 years of age: 15 years of experience. J Heart Valve Dis 1995; 4: 279-83.

5. Harada Y, Imai Y, Kurosawa H, Ishihara K, Kawada M, Fukuchi S. Ten-year follow-up after valve replacement with the St. Jude medical prosthesis in children. J Thorac Cardiovasc Surg 1990; 100: 175-80.

6. Ibrahim M, Cleland J, O' Kane H, Gladstone D, Mullholland C, Craig B. St. Jude medical prosthesis in children. J Thorac Cardiovasc Surg 1994; 108: 52-6.

7. Borman JB, Shimon DV, Deeb M, Simcha A. Valve replacement in children. JCard Surg 1989; 4: 260-81

8. Snitcowsky R. Evolução tardia do implante de prótese de dura-máter em posição mitral. Estudo de pacientes com idades inferiores a 16 anos. (Tese de doutoramento). São Paulo: Universidade de São Paulo, 1983.

9. Godoy MF, Branco JNR, Soares HC, et al. Resultados a longo prazo da substituição valvar em crianças. Arq Bras Cardiol 1981; 37: 325-9.
10. Salles CA, Christo MC, Stortini MJ, et al. Resultados iniciais com a bioprótese heteróloga de Carpentier-Edwards. Arq Bras Cardiol 1981; 36: 349-52.

11. Antunes MJ. Bioprosthetic valve replacement in children: long-term follow-up with 135 mitral valve implantations. Eur Heart J 1984; 5: 913-8.

12. AbidF, Mzah N, Euch FE, Ismail MB. Valve replacement in children under 15 years with rheumatic heart disease. Pediatr Cardiol 1989; 10: 199-204.

13. Cabalka AK, Emery RW, Petersen RJ, et al. Long-term follow-up of the St. Jude medical prosthesis in pediatric patients. Ann Thorac Surg 1995; 60: S618-23.

14. Guvendik L, Cobanoglu A, Davis NR, Fessler CL, Starr A. Valve replacement in children under 14 years of age: a review of 22 years of experience. Eur J Cardiothorac Surg 1989; 3: 229-34.

15. VerrierED, Tranbaugh RF, Soifer SJ, Yee ES, Turley MD, Ebert PA. Aspirin anticoagulation in children with mechanical aortic valves. J Thorac Cardiovasc Surg 1986; 92: 1013-20.

16. Zabal C, Attie F, Barragan R, Buendia A, Duque MP. Resultado tardio del cambio valvular mitral en 155 sujetos menores de 16 años. Estudio comparativo con cuatro protesis. Arch Inst Cardiol Mex 1992; 62: 333-8.

17. LupinettiFM, WarnerJ,Jones TK, Herndon SP.Comparison of humanand mechanical prosthesis for aortic valve replacement in children. Circulation 1997; 96: 321-5.

18. Mazzitelli D, Guenther T, Schreiber C, Wottke M, Michel J, Meisner H. Aortic valve replacement in children: are we on the right track? Eur J Cardiothoracic Surg 1998; 13: 565-71. 